\title{
Evaluation of Forage Yield and Quality in Wild Soybeans (Glycine soja Sieb. and Zucc.)
}

\author{
Eun Ja Lee ${ }^{1}$, Hong-Jib Choi ${ }^{1}$, Dong-Hyun Shin ${ }^{2}$, Chan-Ho Kwon ${ }^{3}$, J. Grover Shannon ${ }^{4}$, Jeong-Dong Lee ${ }^{2 *}$ \\ ${ }^{1}$ Gyeongsangbuk-do Agricultural Research and Extension Services, Daegu 702-708, Republic of Korea \\ ${ }^{2}$ School of Applied Biosciences, Kyungpook National University, Daegu 702-701, Republic of Korea \\ ${ }^{3}$ College of Animal Science, Dept. of Horse/Companion and Wild Animal Science, Kyungpook National University, Sangju 742-711, \\ Republic of Korea \\ ${ }^{4}$ Division of Plant Sciences, University of Missouri-Delta Center, Portageville, MO 63857, USA
}

\begin{abstract}
Wild soybeans (Glycine soja Sieb. \& Zucc.) are generally higher in protein and lower in oil with potential advantages as forage than cultivated soybeans. This study was conducted to evaluate forage yield and quality of wild soybeans. Three wild soybeans were compared to three cultivated soybeans for forage yield and quality at the full bloom stage, full pod stage, and full seed stage (R6) of development. The wild soybeans had significantly lower forage yield than cultivated soybeans at R6 which was determined to be the best stage to harvest based on forage quantity and quality. Wild soybean also had lower crude fat (2.0\%) and crude protein $(17.7 \%)$ concentration than cultivated soybean (5.7 and $21.3 \%$, respectively) at the R6 stage. There were no significant differences for neutral detergent fiber, acid detergent fiber and relative feed value among growth stages between cultivated and wild soybean. The neutral detergent fiber was 40.2 and $40.4 \%$, acid detergent fiber was $26.1 \%$ and $27.5 \%$, and relative feed value was 161 and 158 at R6 stage for cultivated and wild soybean, respectively. Wild soybean had less forage yield at harvest time but had similar forage quality comparable to cultivated soybean. However, wild soybeans have smaller and softer stems for potentially improved palatability and feed intake than cultivated soybeans. Therefore, it will be a good genetic source to improve forage characteristics of soybean.
\end{abstract}

Keywords Soybean, Wild soybean, Forage, Forage quality

\section{INTRODUCTION}

Soybean [Glycine max (L.) Merr.], an edible legume, is one of the most important major crops in the world along with rice and wheat since its seed is high in protein and other nutrients for humans and animals. Soybean has high value not only as food but as a raw material for the various industrial products, bio-energy, and forages. Soybean is high in protein in the hay as well as in the grain, thus it is used as a supplement to other forages in which protein concentration is deficient (Albro et al. 1993).

Soybean was introduced to the USA in the mid-1800s and was historically planted as forage and hay crop (Arny 1926). During the early $20^{\text {th }}$ century, research showing the soybean's value as forage for silage or hay progressed and was well accepted. Hackleman (1924) concluded that soybeans were the best annual nitrogenous seed and hay-producing plant among legumes.

Later in the century, soybeans were evaluated for forage quality and yield. Crude protein (CP) concentrations of soybean hay generally ranges from 12 to $14 \%$ for stems, 19 to $20 \%$ for leaves, and 12 to $27 \%$ for pods, depending on the stage of development (Miller et al. 1973). Hintz et al. (1992) observed that the CP concentrations declined from R1 (beginning bloom stage) to R3 (beginning pod stage), remained constant between R3 and R5 (beginning seed stage), but then increased from R5 to R7 (beginning maturity stage). Neutral detergent fiber (NDF), acid detergent fiber (ADF) and acid detergent lignin (ADL) concentrations increased from R1 to R5 and then decreased

Received February 5, 2014; Revised February 25, 2014; Accepted March 2, 2014; Published March 31, 2014

*Corresponding author Jeong-Dong Lee, jdlee@knu.ac.kr, Tel: +82-53-950-5709, Fax: +82-53-958-6880 
from R5 to R7. Also, at the R5.5 growth stage (between beginning seed and full seed), average CP was $15.5 \%$, ADF was $36.2 \%$ and NDF was $46.9 \%$ (Seiter et al. 2004). Soybean forage harvested at R7 showed similar quality levels as those of alfalfa hay harvested at early bloom stage of development (NRC 1989).

Wild soybean (Glycine soja Sieb. \& Zucc.) is the ancestor of cultivated soybean and is widely distributed in China, Japan, Korea, Taiwan and eastern Russia (Hymowitz and Singh 1987). Wild soybeans crossed naturally with the cultivated soybeans showed relatively vigorous growth even under infertile soil and dry environment conditions (Hymowitz 1970).

Since wild soybeans grow naturally and are common in Asia, farmers have used them as forage for centuries. Forage quality and yield for wild soybean have been reported. According to Lee et al. (1993), the CP contained in the leaves and the seeds of wild soybeans were $28 \%$ and $46 \%$, respectively and around $17 \%$ in the whole plant. The NDF concentrations were $50 \%, 48 \%$, and $62 \%$ each in the leaves, seeds, and the whole plants, respectively. ADF concentrations in the leaves, seeds, and whole plants were $28 \%, 28 \%$, and $45 \%$, respectively. Zhai et al. (2008) reported that dry matter yield harvested from earliest to latest soybean growth stages ranged from 2.3 to $6.5 \mathrm{t} \mathrm{ha}^{-1}$. Mean nutritional components were $19.1 \%$, $35.5 \%$, and $25.4 \%$ for $\mathrm{CP}, \mathrm{NDF}$, and $\mathrm{ADF}$, respectively indicating that wild soybeans are good forage crop.

Limited results have revealed that cultivated and wild soybeans are comparable as forage crops. However, there are few studies accessing the value of wild soybeans as forage or as potential source to use in breeding to improve forage soybeans. Since wild soybeans are common in Korea, this study was conducted to evaluate the yield and quality of wild soybeans as forage in comparison to cultivated soybeans harvested at the three developmental stages.

\section{MATERIALS AND METHODS}

\section{Field trials}

Evaluation of forage yield and quality during different developmental stages of cultivated soybeans and wild soybeans was conducted over two years (2010 and 2011) in the experimental field of Gyeongsangbuk-do Agricultural Research and Extension Services in Daegu, Republic of Korea. There is no cultivated forage soybeans specifically developed for Korea. Therefore, three cultivated soybeans, Daewonkong (Kim et al. 1998), Pungsannamulkong (Suh et al. 1997), and Bosug (Oh et al. 2003) were used to compare with the three wild accessions (IT184141, KLG12807, and KLG12816) that were collected from central Korea. Planting was done on July 2, 2010, May 20 and June 20, 2011. The plot size was $4.8 \mathrm{~m}^{2}$ (2.4m wide $\times$ $2 \mathrm{~m}$ long, four rows per plot). Each of the six soybean lines was planted in hills in rows spaced $60 \mathrm{~cm}$ apart. Hills within rows were spaced at $15 \mathrm{~cm}$ intervals with one seedling per hill. The experiment was laid out in split-plot with three replications. Cultivars and growth stages were regarded as main plots and subplots, respectively. Each plot was fertilized with $80-80-90 \mathrm{~kg} / \mathrm{ha}^{-1}$ of $\mathrm{N}-\mathrm{P}_{2} \mathrm{O}_{5}-\mathrm{K}_{2} \mathrm{O}$. Weed control was carried out manually and all plots were kept weed free. The forage yield and quality were evaluated at, R2 (full bloom), R4 (full pod), and R6 (full seed) growth stages (Fehr et al. 1971). Yield was taken as the fresh weight and the dry matter of plants from the two center rows of each plot. To determine the dry matter concentration, plant samples from each plot were oven-dried at $65^{\circ} \mathrm{C}$ for at least $72 \mathrm{~h}$ or until dry. Then, the fresh weight was multiplied with the dry matter concentration. All the samples used in the experiment were dried with the same method as above.

\section{Chemical analyses}

Forage quality, such as $\mathrm{CP}$, crude fat $(\mathrm{CF}), \mathrm{ADF}$, $\mathrm{NDF}$, digestible dry matter (DDM), dry matter intake (DMI), and relative feed value (RFV) were analyzed for each sample harvested from different reproductive stages.

Dried samples were ground in a 20 mesh Wiley mill (Ultra centrifugal mill ZM 200, Retsch, Germany) for the analyses. Moisture contents were measured by using a Moisture meter (MA35, Satorius, Germany). The CP was analyzed by the Dumas method according to AOAC (2011). The $\mathrm{CP}$ concentration $(\% \mathrm{CP}=\% \mathrm{~N} \times 6.25)$ was determined by measuring nitrogen concentration after combustion of a $200 \mathrm{mg}$ sample at $1,200^{\circ} \mathrm{C}$ using 
an Elemental Analyzer (Vario Max CNS, Elementar, Germany). The CF concentration was determined from two gram plot samples using an automatic Soxhlet extractor (Soxtherm, Gerhardt, Germany) according to the AOAC (2011) method. The solvent used for the CF extraction was petroleum ether.

The ADF and NDF were determined from $0.5 \mathrm{~g}$ plot samples using a Fiber Analyzer (ANKOM ${ }^{2000}$ Fiber Analyzer, Ankom Technology, Macedon NY) based on the methods in Goering \& Van Soest (1970) and Van Soest \& Robertson (1980). The solvent used for the ADF was acid detergent solution (FAD20C, ANKOM Tech.), while for NDF analysis neutral detergent solution (FND20C, ANKOM Tech.), sodium sulfate, and heat stable alpha-amylase were used. DMI was estimated based on the analyzed NDF concentration of the forage $(\mathrm{DMI}=120 / \mathrm{NDF})$. DDM was calculated from the analyzed ADF concentration of the forage $(\mathrm{DDM}=88.9-(0.779$ $\times \mathrm{ADF})$ ). RFV reflects how well an animal will eat and digest particular forage if it is fed as the only source of energy. The RFV was calculated as an index representing the intake rate and digest rate by using an equation RFV $=(\mathrm{DDM} \times \mathrm{DMI}) / 1.29($ Holland et al. 1990) .

\section{Data analysis}

All the results of experiment were analyzed for ANOVA using General Linear Model procedure of SAS (version 9.2, by SAS Institute, Inc., Cary, NC, USA). Comparisons of significance for each factor were carried out at the 0.05 level of significance using the least significant difference test and t-test.

\section{RESULTS}

\section{Analysis of variance for forage related characters}

ANOVAs for different variables are shown in Table 1. Multi-environment tests revealed that the fresh and dry matter yield of forage was affected by growing environment (E) $(P<0.0002)$, genotype $(\mathrm{G})(P<0.0001)$ and growth stage (S) $(P<0.001)$. Also $\mathrm{E} \times \mathrm{G}, \mathrm{E} \times \mathrm{S}, \mathrm{G} \times \mathrm{S}$, and $\mathrm{E} \times \mathrm{G}$ $\times \mathrm{S}$ interactions were significant for the fresh and dry

Table 1. Analysis of variance for fresh weight $(\mathrm{FW})$, dry matter (DM), crude fat (CF), crude protein (CP), neutral detergent fiber (NDF), acid detergent fiber (ADF), and relative feed value (RFV) in soybean forage over three environments $^{\mathrm{z})}$, for six soybean $\operatorname{accessions}^{\mathrm{y})}$, harvested at three growth stages $^{\mathrm{x}}$.

\begin{tabular}{ccrrrrrrr}
\hline \hline & df & \multicolumn{7}{c}{ F-value } \\
\cline { 3 - 8 } & & \multicolumn{1}{c}{ FW } & \multicolumn{1}{c}{ DM } & \multicolumn{1}{c}{ CF } & \multicolumn{1}{c}{ CP } & NDF & \multicolumn{1}{c}{ ADF } & \multicolumn{1}{c}{ RFV } \\
\hline Environments (E) & 2 & $50.40^{* *}$ & $132.37^{* *}$ & $0.21^{\text {ns }}$ & $350.56^{* *}$ & $14.23^{* *}$ & $51.01^{* *}$ & $13.56^{* *}$ \\
Replication (E) & 6 & $3.40^{* *}$ & $1.12^{\text {ns }}$ & $2.96^{*}$ & $0.50^{\text {ns }}$ & $2.48^{*}$ & $0.89^{\text {ns }}$ & $2.21^{*}$ \\
Genotype (G) & 5 & $65.97^{* *}$ & $49.04^{* *}$ & $34.41^{* *}$ & $46.54^{* *}$ & $3.25^{* *}$ & $10.49^{* *}$ & $3.44^{* *}$ \\
Growth stage (S) & 2 & $580.04^{* *}$ & $613.51^{* *}$ & $165.91^{* *}$ & $59.51^{* *}$ & $10.06^{* *}$ & $103.98^{* *}$ & $19.20^{* *}$ \\
E $\times$ G & 10 & $33.33^{* *}$ & $23.72^{* *}$ & $4.79^{* *}$ & $14.27^{* *}$ & $6.04^{* *}$ & $6.59^{* *}$ & $5.07^{* *}$ \\
E $\times$ S & 4 & $5.59^{* *}$ & $10.17^{* *}$ & $1.61^{\text {ns }}$ & $15.07^{* *}$ & $11.76^{* *}$ & $14.28^{* *}$ & $11.03^{* *}$ \\
G $\times$ S & 10 & $33.84^{* *}$ & $24.35^{* *}$ & $18.65^{* *}$ & $10.10^{* *}$ & $1.69^{\text {ns }}$ & $3.52^{* *}$ & $1.37^{\text {ns }}$ \\
E $\times$ G $\times$ S & 20 & $4.46^{* *}$ & $4.37^{* *}$ & $0.92^{\text {ns }}$ & $2.85^{* *}$ & $2.02^{*}$ & $1.97^{*}$ & $1.10^{\text {ns }}$ \\
\hline Total & 161 & & & & & & &
\end{tabular}

\footnotetext{
${ }^{* *}$ Significant at the 0.01 level of probability.

${ }^{*}$ Significant at the 0.05 level of probability.

ns, not significant at the 0.05 level of probability.

${ }^{2)}$ The environments included three different planting date (2 July 2010, 20 May 2011 and 20 June, 2011).

${ }^{\mathrm{y}}$ G. $\max$ entries were Daewonkong, Pungsannamulkong, and Bosug. G. soja entries were IT184141, KLG12807, and KLG12816.

${ }^{\mathrm{x})}$ Three harvest stages were R2 (full bloom stage), R4 (full pod stage), and R6 (full seed stage).
} 
matter yield of the forage. The $\mathrm{E}, \mathrm{E} \times \mathrm{S}$ and $\mathrm{E} \times \mathrm{G} \times \mathrm{S}$ interactions were not significant for $\mathrm{CF}$ concentration. Most of the variance and interactions for $\mathrm{CP}, \mathrm{NDF}, \mathrm{ADF}$, and RFV were significant. The $\mathrm{G} \times \mathrm{S}$ and $\mathrm{E} \times \mathrm{G} \times \mathrm{S}$ interactions were not significant for RFV (Table 1).

Comparison of forage yield and quality between $G$. max and G. soja, among growth stages

Fresh weight and dry matter yield of soybean forage increased from growth stages R2 to R6 in cultivated soybean (Fig. 1 and Table 2). The average fresh forage yield of cultivated soybeans were $4.4 \mathrm{tha}^{-1}(\mathrm{R} 2), 12.7 \mathrm{tha}^{-1}$
(R4), and $16.3 \mathrm{tha}^{-1}$ (R6), and the average dry matters were $0.9 \mathrm{t} \mathrm{ha}^{-1}(\mathrm{R} 2), 3.4 \mathrm{tha}^{-1}(\mathrm{R} 4)$, and $4.9 \mathrm{tha}^{-1}$ (R6). This trend was similar for fresh weight and dry matter yield changes among growth stages in wild soybean. The average fresh weight of wild soybean were $6.1 \mathrm{t} \mathrm{ha}^{-1}(\mathrm{R} 2), 8.9 \mathrm{t} \mathrm{ha}^{-1}(\mathrm{R} 4)$, and $9.9 \mathrm{tha}^{-1}$ (R6), and the average dry matters were $1.3 \mathrm{t}$ $\mathrm{ha}^{-1}$ (R2), $2.3 \mathrm{t} \mathrm{ha}^{-1}$ (R4), and $2.9 \mathrm{tha}^{-1}$ (R6).

The forage fresh weight and dry matter yield between cultivated soybean and wild soybean were not significantly different at R2. However, cultivated soybeans averaged significantly higher $(\mathrm{P}<0.05)$ at $\mathrm{R} 4$ and $(\mathrm{P}<0.01)$ at $\mathrm{R} 6$ in forage yield than in wild soybeans (Table 2). When average
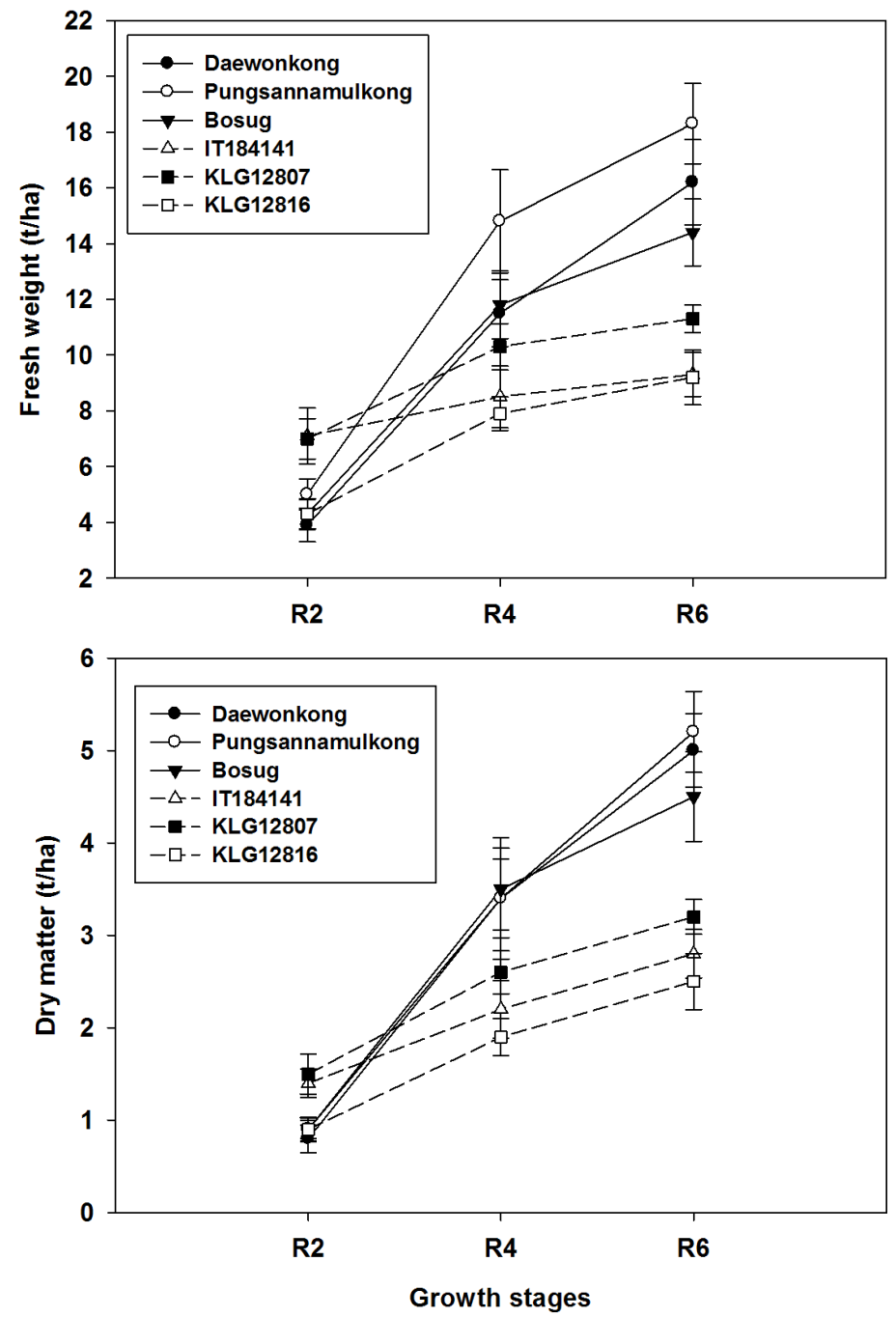

Fig. 1. Forage yield (fresh weight and dry matter) for six soybeans as growth stages (R2 : full bloom stage, R4 : full pod stage, R6 : full seed stage) averaged over three environments (planted at 2 July 2010, 20 May 2011, and 20 June 2011). Solid lines are for G. max and dashed lines are G. soja accessions. Bar means standard error calculated from three planting dates. 
yield was taken across all soybean accessions and environments, the forage yield significantly increased as soybean maturity progressed from R2 to R6 (Table 2).

The differences in CF, CP, NDF, ADF, and RFV at different growth stages are presented in Fig. 2 and Table 2. $\mathrm{CF}$ concentration in general, was constant from R2 to R4 in both cultivated and wild soybeans. However, a significant increase was noted from R4 to R6 (Fig. 2 and Table 2). The difference for $\mathrm{CF}$ between cultivated and wild soybean at R2 (1.6\% and $1.5 \%$, respectively) and R4 (1.7\%, and $1.2 \%$, respectively) was not significant, however cultivated soybean accumulated more CF at R6 (5.7\%) stage than wild soybeans $(2.0 \%)$. Mean CF concentrations of all the soybean accessions used in this experiment were not significantly different from R2 (1.5\%) to R4 (1.5\%) but it increased significantly from R4 to R6 (3.9\%).

$\mathrm{CP}$ increased in cultivated soybeans as maturity progressed from R2 to R6 (Table 2 and Fig. 2). CP concentrations increased in Daewonkong from earliest to latest growth stage $(15.8 \%$ at R2, $18.4 \%$ at R4 and $21.0 \%$ at R6), while it was constant in Bosug from R2 (16.9\%) to R4 (16.9\%) and increased at R6 to $20.9 \%$. CP was relatively constant and not significantly different over growing periods (20.9\% at R2, $20.6 \%$ at R4 and $22.1 \%$ at R6) for Punsannamulkong.
On the contrary, CP significantly increased in wild soybeans from R2 (16.1\%) to R4 (18.2\%) and then decreased from R4 to R6 (17.7\%) but the decrease was not significantly different from the value at R4. CP concentrations in general, increased in IT184141 and KLG12807 from R2 (16.4\% and 16.1\%) to R4 (18.0\% and $17.3 \%)$ and then decreased from R4 to R6 (18.0\% and $16.1 \%$ ), but the differences were not significant as growth progressed from R2 to R6. In KLG12816, CP significantly increased from R2 (15.9\%) to R4 (19.5\%) and decreased slightly from R4 to R6 (19.0\%) (Fig. 2 and Table 2).

The NDF value tended to decrease from R2 to R6 stages. Decreasing trends in NDF were observed in Bosug, IT184141, KLG12807, and KLG12816 as growth stages progressed from R2 to R6. On the other hand, NDF in two cultivated soybean genotypes, Pungsannamulkong and Daewonkong, responded differently as harvest was delayed. NDF values increased from R2 (40.7\%) to R6 $(41.3 \%)$ in Pungsannamulkong, while it increased in Daewonkong from R2 (40.3\%) to R4 (42.5\%) followed by a decrease (39.2\%) at R6 but in general, most of individual NDF values for each accession were not significantly different (Fig. 2). Though mean NDF concentrations in cultivated soybeans did not significantly change from R2 $(41.2 \%)$ to R4 (42.0\%), a significant decrease in NDF was

Table 2. Comparison of forage yield and quality between $G$. $\max$ and G. soja at three harvest stages averaged over three environments ${ }^{\mathrm{x} \text { ) }}$.

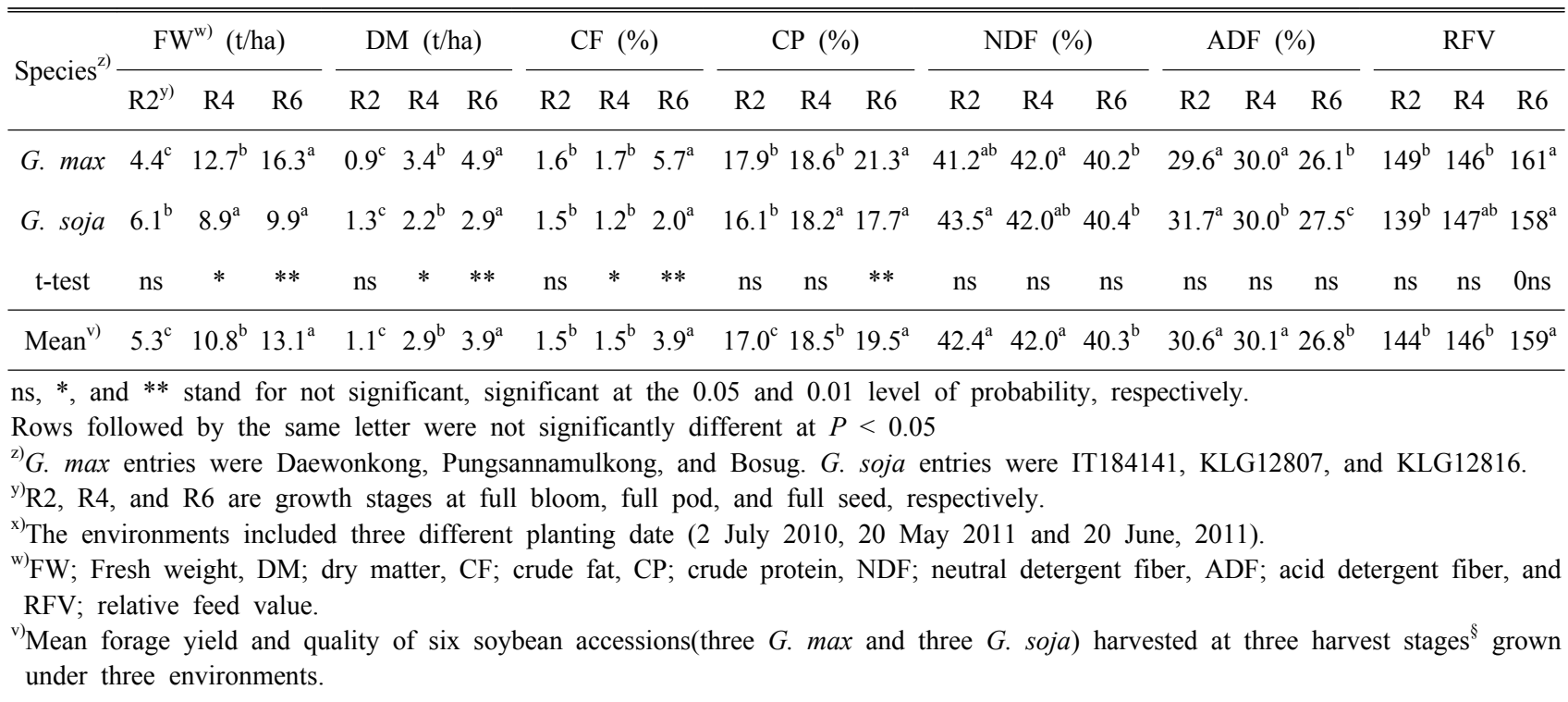


observed from R4 to R6 (40.2\%). However, average NDF values in wild soybeans significantly decreased from R2 (43.5\%) to R6 (40.4\%). There was no difference for NDF values at each growth stage between cultivated and wild soybean. When average was computed across all soybean
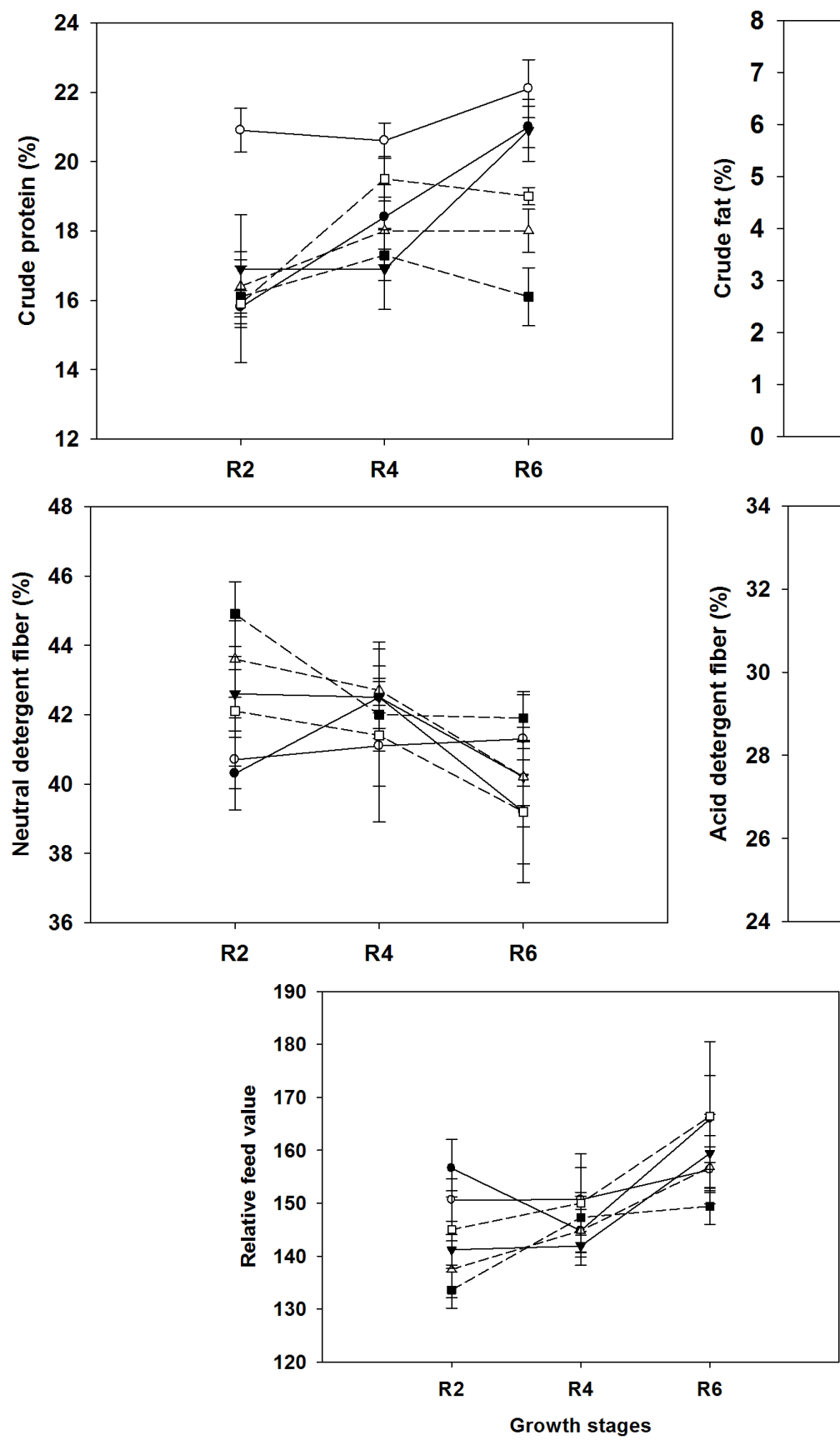

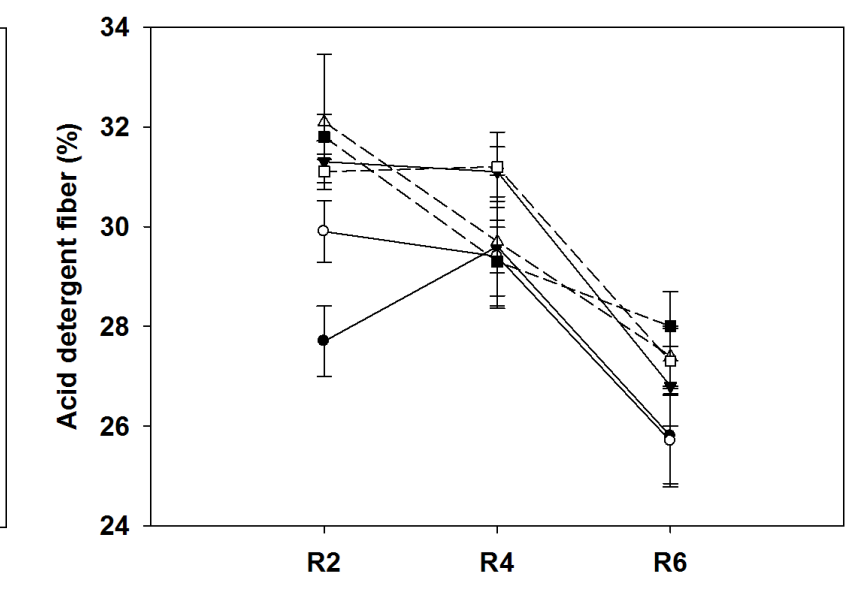

accessions, the NDF values decreased from R2 to R4 but differences were not significant; however NDF significantly decreased from R4 (42.0\%) to R6 (40.3\%) (Table 2).

The ADF value also tended to decrease as harvest growth stages progressed. ADF slightly increased in Daewonkong

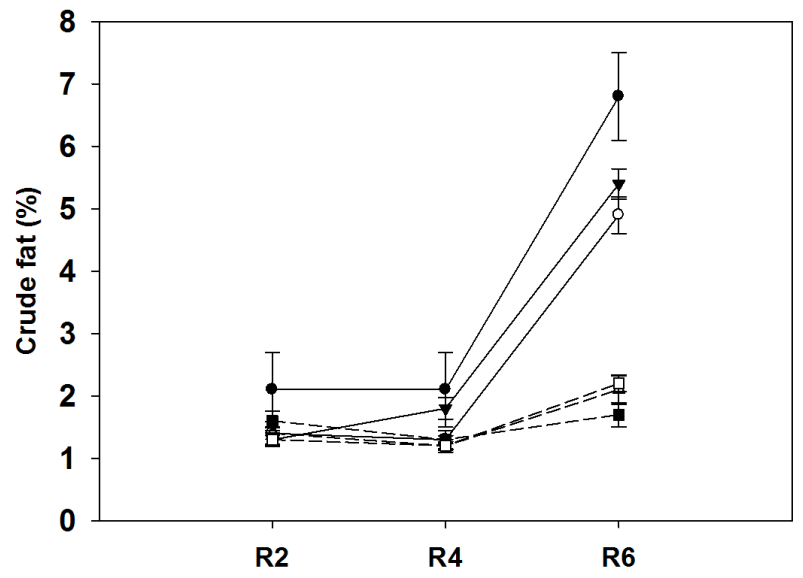

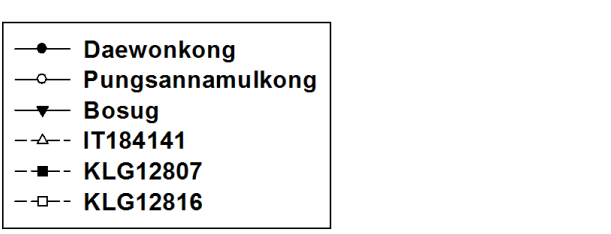

Fig. 2. Forage quality at different growth stages (R2 : full bloom stage, R4 : full pod stage, R6 : full seed stage) for six soybeans averaged over three environments (planted 2 July 2010, 20 May 2011, and 20 June, 2011). Solid lines are G. max, dashed lines are G. soja accessions. Bar means standard error calculated from three planting dates. 
from R2 (27.7\%) to R4 (29.6\%) but decreased from R4 to R6 (25.8\%) while there was no change in Pungsannamulkong, Bosug, and KLG12816 from R2 to R4 followed by a decrease from R4 to R6 stage. The ADF concentrations in IT184141 and KLG12807 showed a decreasing trend as harvest was delayed from R2 to R6 in this study (Fig. 2).

Mean ADF value in the cultivated soybeans was not significantly different from R2 (29.6\%) to R4 (30.0\%), but significantly decreased from R4 to R6 (26.1\%). On the other hand, ADF significantly decreased in the wild soybeans from R2 (31.7\%) to R6 (27.5\%). Mean ADF value across soybean accessions (Table 2) was not significantly different from R2 (30.6\%) to R4 (30.1\%) but significantly decreased from R4 to R6 (26.8\%). There were no significant differences between cultivated and wild soybeans for ADF at any of the harvest growth stages.

Generally, RFV increased from R2 to R6. However, soybean accessions showed slightly different patterns for RFV from earliest to latest growth stages (Table 2 and Fig. 2). Cultivar Daewonkong decreased in RFV from R2 (156.6) to R4 (144.8) and then sharply increased at R6 (165.9). Bosug's RFV was almost constant from R2 (141.2) to R4 (141.9) then increased from R4 to R6 (159.4). The RFV in Pungsannamulkong and KLG12816 generally increased as harvest stages moved from flowering to maturity but differences were not significant. IT184141 showed a significant increase in RFV from R2 (137.5) to R6 (156.3). RFV significantly increased from R2 (133.6) to R4 (147.3), but it was constant after stage R4 in KLG12807 (Fig. 2). There was no significant difference for RFV at the three growth stages when averaged over accessions between cultivated and wild soybean. Mean RFV across soybean accessions showed no differences between R2 (144) and R4 (146), but was higher at the R6 stage (159) than earlier growth stages.

\section{DISCUSSION}

Soybean has historically been used as a forage crop and evaluated for forage yield and quality. Most previous studies reported that the forage yield increased from early reproductive stage (R1) to early maturity growth stages (R6 or R7) (Rao et al. 2005; Sheaffer et al. 2001; Hintz et al. 1992). In this study similar results were obtained with the previous reports. The wild and cultivated soybean accessions we evaluated had the highest forage yield at R6 stage which were significantly higher than the values obtained at the R2 and R4 growth stages (Fig. 1 and Table 2).

Hintz et al. (1992) observed that CP concentrations declined from R1 to R3, remained constant between R3 and R5 but increased from R5 to R7. NDF and ADF concentrations increased from R1 to R5 and then decreased from R5 to R7. Seiter et al. (2004) found that CP, ADF, and ADF increased from R3 to R5.5. Munoz et al. (1983) noted that CP concentration increased significantly beyond R5. Zhai et al. (2008) planted three wild soybeans lines on April 29 and harvested soybeans for forage five times at 20 days intervals. They reported that $\mathrm{CP}$ concentrations decreased as forage harvest was delayed throughout the growing period. NDF concentrations increased from the first until the fourth harvest growth stage and then decreased but the decrease was not significant. Also, ADF concentrations increased until the third harvest growth stage and then decreased afterwards.

The differences among results of previous research for the forage quality seem to be related to variety of soybeans used in the experiments and differences in the growth stages. For example, Hintz et al. (1992) used only three varieties of cultivated soybeans for the experiment, while Seiter et al. (2004) used only one forage soybean. Zhai et al. (2008) used three lines of wild soybeans, while Munoz et al. (1983) used only cultivated soybean varieties for their experiment.

We also evaluated several forage parameters such as $\mathrm{CF}$, $\mathrm{CP}, \mathrm{ADF}$, and NDF for wild and cultivated soybeans (Fig. 2 and Table 2). The results for forage quality by growth stages showed that the $\mathrm{CF}$ concentration was similar at $\mathrm{R} 2$ and R4, and peaked at R6 in both wild- and cultivated soybean types.

In the cultivated soybean $\mathrm{CP}$ concentrations varied among the three cultivars from R2 to R4 but increased and were highest at R6 which was consistent with the results by Hintz et al. (1992). However, the CP concentrations in the wild soybean were either constant or decreased after R4. This tendency was a little different 
from the results by Zhai et al. (2008), but was consistent with tendency for $\mathrm{CP}$ to decrease in wild soybean as harvest growth stages was delayed unlike cultivated soybeans in which $\mathrm{CP}$ was highest when harvest was at latest growth stages.

In general, NDF and ADF concentrations showed the largest values at R4 in cultivated soybeans followed by a decrease after R4 which was similar to results reported by Hintz et al. (1992) and Zhai et al. (2008), whereas NDF and ADF concentrations in the wild soybeans decreased after R2.

At R6, average NDF and ADF of cultivated soybeans were $41.2 \%, 26.6 \%$, and an average NDF and ADF of wild soybeans were $40.4 \%, 27.5 \%$, respectively. These values were classified as forage Grade 1 according to Standard of Forage Quality by American Forage and Grassland Council. The RFV was 161 and 158 at R6 stage for cultivated and wild soybean, respectively. Overall, in both cultivated and wild soybean, the R6 was the optimal harvest stage to provide forage of high quality and adequate quantity for animals. This is consistent with the previous researches which have shown that the optimal harvest stage is at R6 to R7 (Willard 1925; Munoz et al. 1983; Hintz et al. 1992).

Based on our results and previous reports (Lee et al. 1993; Zhai et al. 2008), wild soybean has comparable forage quality with cultivated soybean (Table 2) for NDF, $\mathrm{ADF}$, and RFV.

Wild soybeans grow naturally throughout in Korea and have been used as forage for many centuries. It has viny growth habit with more slender stems than cultivated soybean which should make wild soybeans easier for cattle to eat. Even though wild soybeans have benefits for feed, it has unfavorable characters such as shattering at maturity and hard seed coats that affect germination for directly planting seed for a forage crop. Fortunately, cultivated soybean and wild soybean hybridize easily and exhibit normal meiotic chromosome pairing. Therefore, wild soybean is a valuable resource to improve cultivated soybean (Concibido et al. 2003; Kabelka et al. 2005; Ha et al. 2013).

We evaluated the forage yield and quality of wild soybean. Wild soybean had less forage yield at various harvest stages but had similar forage quality compared to cultivated soybean. However, cultivated soybean generally has harder and bigger stems, which are often less palatable for cattle than forage from wild soybean with smaller and softer stems. It is possible through hybridization between cultivated and wild soybean to develop semi-wild type soybeans without hard seed, shattering at maturity, and semi-erect, indeterminate plants with thinner stems and as much biomass as cultivated soybean. Soybeans with these traits will facilitate the use of soybeans in cropping systems for production of high quality forage for soybean monocropping, and for mixed planting of corn and soybean. Thus, wild soybean will likely be a good genetic source to improve yield and quality of forage soybean. More studies among selections from crosses of cultivated $\mathrm{x}$ wild soybeans are necessary to truly access the value of wild soybeans to improve soybean as a forage crop.

\section{ACKNOWLEDGMENT}

This research was supported by Bio-industry Technology Development Program (110018-4), Ministry of Agriculture, Food and Rural Affairs, Republic of Korea

\section{REFERENCES}

Albro JD, Weber DW, DelCurto T. 1993. Comparison of whole, raw soybeans, extruded soybeans, or soybean meal and barley on digestive characteristics and performance of weaned beef steers consuming mature grass hay. J. Anim. Sci. 71: 26-32.

Arny AC. 1926. The influence of time of cutting on the quality of crops. Agron. J. 18: 684-703.

AOAC. 2011. Official methods of analysis. 18th ed. AOAC INTERNATIONAL; Gaithersburg, Maryland, USA.

Concibido VC, Valle BL, Mclaird P, Pineda N, Meyer J, Hummel L, Yang J, Wu K, Delannay X. 2003. Introgression of a quantitative trait locus for yield from Glycine soja into commercial soybean cultivars. Theor. Appl. Genet. 106: 575-582.

Fehr WR, Cavines CE, Burmood DT, Pennington JS. 1971. Stage of development descriptions for soybeans, Glycine $\max$ (L.). Merrill. Crop Sci. 11: 929-931.

Goering HK, Van Soest PJ. 1970. Forage fiber analysis 
(apparatus, reagents, procedures and some applications). Agricultural Handbook 379. USDA-ARS, Govt. USA, Washington, DC.

Ha BK, Vuong TD, Velusamy V, Nguyen HT, Shannon JG, Lee JD. 2013. Genetic mapping of quantitative trait loci conditioning salt tolerance in wild soybean (Glycine soja) PI 483463. Euphytica 193: 79-88.

Hackleman JC. 1924. The future of the soybean as a forage crop. Agron. J. 16: 228-236.

Hintz RW, Albrecht KA, Oplinger ES. 1992. Yield and quality of soybean forage as affected by cultivar and management practices. Agron. J. 84: 795-798.

Holland C, Kezar W, Kautz WP, Lazowski EJ, Mahanna WC, Reinhart R. 1990. The pioneer forage manual. A nutritional guide. Pioneer Hi-Bred Int. Inc., Des Moines, LA.

Hymowitz T. 1970. On the domestication of soybean. Econo. Bot. 24: 408-421.

Hymowitz T, Singh RJ. 1987. Taxonomy and speciation. In: Wilcox JR (ed.). Soybeans: Improvement, production and uses. Agronomy Monograph no. 16. 2nd ed. p.2348. ASA and CSSA publications, Madison, WI.

Kabelka EA, Carlson SR, Diers BW. 2005. Localization of two loci that confer resistance to soybean cyst nematode from Glycine soja PI468916. Crop Sci. 45: 2473-2481.

Kim SD, Park KY, Kim YH, Yun HT, Lee YH, Lee SH, Seung YK, Park EH, Hwang YH, Ryu YH, Hwang CJ, Kim YS. 1998. A new soybean variety for soy paste with large seed and disease resistant "Daewonkong". RDA. J. Crop Sci. 40: 107-111.

Lee SK, Lee E, Choi I. 1993. Studies on the domestication of field bean (Glycine soja Sieb and Zucc) for forage crop. J. Korean Grassl. Sci. 13: 86-92.

Miller MD, Edwards RT, Williams WA. 1973. Soybean for forage and green manure. In: Beard $\mathrm{BH}$ and Knowles
PF (ed.). Soybean research in California, p.60-66. California Agricultural Experiment Station. Bulletin. 862.

Munoz AE, Holt EC, Weaver RW. 1983. Yield and quality of soybean hay as influenced by stage of growth and plant density. Agron. J. 75: 147-149.

National Research Council. 1989. Nutrient requirements of dairy cattle. 6th ed. National Academy Science, Washington, DC.

Oh YJ, Kim KH, Suh SK, Park HK, Lee MJ, Kim HS, Kim YJ, Kim SD, Lee SH. 2003. A new soybean variety for sprout with small seed size resistance and high yielding "Bosug”. Kor. J. Breed. Sci. 37: 109-110.

Rao SC, Mayeux HS, Northup BK. 2005. Performance of forage soybean in the southern Great Plains. Crop Sci. 45: 1973-1977.

Seiter S, Altemose CE, Davis MH. 2004. Forage soybean yield and quality responses to plant density and row distance. Agron. J. 96: 966-970.

Sheaffer CC, Orf JH, Devine TE, Jewett JG. 2001. Yield and quality of forage soybean. Agron. J. 93: 99-106.

Suh SK, Kim HS, Oh YJ, Kim KH, Cho SK, Kim YJ, Kim SD, Park HK, Park MS, Cho SY. 1997. A new soybean variety for sprout with small seed and high yielding "Pungsan-namulkong”. Kor. J. Breed. Sci. 29: 503.

Van Soest PJ, Robertson JB. 1980. Systems of analysis for evaluating fibrous feeds. In: Pigden WJ et al. (ed.). Proc. Int. Workshop on standardization Anal. Meth. Feeds. p.49-60. Ottawa, Canada. 12-14 Mar. 1979.

Willard CJ. 1925. The time of harvesting soybeans for hay and seed. Agron. J. 17: 157-168.

Zhai G, Shen Y, Zhai Y, Liu X, Jiang H. 2008. Forage yield performance and nutritive value of selected wild soybean ecotypes. Can. J. Plant Sci. 88: 465-472. 